\title{
Magnetic resonance imaging of the chest in the evaluation of cancer patients: state of the art $^{*}$
}

\author{
Ressonância magnética do tórax na avaliação dos pacientes oncológicos: estado da arte
}

Marcos Duarte Guimaraes ${ }^{1}$, Bruno Hochhegger ${ }^{2}$, Marcel Koenigkam Santos ${ }^{3}$, Pablo Rydz Pinheiro Santana ${ }^{4}$ Arthur Soares Sousa Júnior ${ }^{5}$, Luciana Soares Souza ${ }^{6}$, Edson Marchiori ${ }^{7}$

Guimaraes MD, Hochhegger B, Koenigkam-Santos M, Santana PRP, Sousa Júnior AS, Souza LS, Marchiori E. Magnetic resonance imaging of the chest in the evaluation of cancer patients: state of the art. Radiol Bras. $2015 \mathrm{Jan} / \mathrm{Fev} ; 48(1): 33-42$.

Abstract Magnetic resonance imaging (MRI) has several advantages in the evaluation of cancer patients with thoracic lesions, including involvement of the chest wall, pleura, lungs, mediastinum, esophagus and heart. It is a quite useful tool in the diagnosis, staging, surgical planning, treatment response evaluation and follow-up of these patients. In the present review, the authors contextualize the relevance of MRI in the evaluation of thoracic lesions in cancer patients. Considering that MRI is a widely available method with high contrast and spatial resolution and without the risks associated with the use of ionizing radiation, its use combined with new techniques such as cine-MRI and functional methods such as perfusion- and diffusion-weighted imaging may be useful as an alternative tool with performance comparable or complementary to conventional radiological methods such as radiography, computed tomography and PET/CT imaging in the evaluation of patients with thoracic neoplasias.

Keywords: Magnetic resonance imaging; Diffusion-weighted imaging; Chest; Thoracic lesions; Oncology.

Resu mo A ressonância magnética (RM) possui diversas vantagens na avaliação de pacientes oncológicos portadores de lesões torácicas, sejam elas lesões de parede, pleurais, pulmonares, mediastinais, esofagianas, cardíacas ou linfonodais. É uma ferramenta bastante útil no manejo destes pacientes, seja no diagnóstico, no estadiamento, no planejamento cirúrgico, na avaliação de resposta ou no seguimento. No presente artigo os autores contextualizam a importância da RM na avaliação das lesões torácicas de pacientes oncológicos. Por se tratar de um equipamento disponibilizado universalmente, sem os riscos da irradiação ionizante, com elevada resolução de contraste e espacial, aliada a novas técnicas como a cine-RM, a perfusão e a difusão, a RM pode atuar como uma ferramenta alternativa, economicamente viável, e com performance comparável ou complementar aos métodos radiológicos convencionais como a radiografia simples, a tomografia computadorizada e a PET/CT na avaliação dos pacientes portadores de neoplasias torácicas.

Unitermos: Ressonância magnética; Difusão; Tórax; Lesões torácicas; Oncologia.

\section{INTRODUCTION}

The incidence of neoplasias has increased globally and currently cancer is one of the main causes of natural death worldwide $^{(1)}$. Thoracic tumors, either primary or metastatic, represent a significant portion of cancer deaths ${ }^{(2)}$. After diagnosis confirmation, the patient with a malignant chest tumor

* Study developed at the Imaging Department of A.C.Camargo Cancer Center, São Paulo, SP, Brazil.

1. PhD, Radiologist, Specialist in Internal Medicine, Responsible for Chest Imaging Units at Hospital Heliópolis and A.C.Camargo Cancer Center, São Paulo, SP, Brazil.

2. PhD, Associate Professor at Universidade Federal de Ciências da Saúde de Porto Alegre (UFCSPA), Porto Alegre, RS, Brazil.

3. PhD, Radiologist at Hospital das Clínicas da Faculdade de Medicina de Ribeirão Preto da Universidade de São Paulo (HCFMRP-USP), Ribeirão Preto, SP, Brazil.

4. MD, Member of Colégio Brasileiro de Radiologia e Diagnóstico por Imagem (CBR), Thoracic Radiologist at Beneficência Portuguesa de São Paulo, São Paulo, SP, Brazil.

5. PhD, Professor and Post-graduation Advisor, Faculdade de Medicina de São José do Rio Preto (Famerp), São José do Rio Preto, SP, Brazil.

6. MD, Radiologist, Faculdade de Medicina São José do Rio Preto (Famerp), São José do Rio Preto, SP, Brazil.

7. PhD, Adjunct Coordinator of Post-Graduation, Universidade Federal do Rio de Janeiro (UFRJ), Rio de Janeiro, RJ, Brazil. should be submitted to appropriate assessment to receive the correct therapeutic option ${ }^{(3)}$. A significant portion of cancer patients present with advanced malignant disease at the time of the diagnosis, which reduces the chances of therapeutic success. However, patients with focal disease should be submitted to treatments that offer real possibilities of healing ${ }^{(4,5)}$. Therefore, it is important the imaging diagnosis tools provide accurate information about the location, number of lesions, tumor extent, disease activity and biomarkers ${ }^{(6)}$. Currently, the set of such information is imprescindible for the most appropriate management of cancer patients, including those with malignant chest tumors ${ }^{(6,7)}$.

Over the last 25 years, magnetic resonance imaging (MRI) has significantly developed, and its use became increasingly disseminated ${ }^{(8)}$. It is available both in several specialized and nonspecialized centers, and has increasingly been employed in the evaluation of malignant chest lesions with several advantages. This imaging method can provide images

Mailing Address: Dr. Marcos Duarte Guimaraes. Rua Paulo Orozimbo, 726, Aclimação. São Paulo, SP, Brazil, 01535-001. E-mail: marcosduarte500@yahoo.com.br. Received September 13, 2013. Accepted after revision February 7, 2014. 
with high contrast and spatial resolution, facilitating the recognition of anatomical planes as well as the identification of abnormalities ${ }^{(9)}$. The multiplanar images acquisition and the resource of three-dimensional reconstruction allow for a comprehensive evaluation of the chest, decisively contributing to the therapeutic planning. Also, it is important the fact that MRI is a method free from ionizing radiation $^{(10,11)}$. When well indicated, MRI can act as complementary or alternative tool in the evaluation of chest tumors, with performance comparable to conventional diagnostic imaging methods such as bone scintigraphy, computed tomography (CT) and PET/CT ${ }^{(12)}$.

The present review article is aimed at approaching relevant aspects connected with MRI in the evaluation of patients with either primary or secondary malignant chest tumors. Recent developments in oncology, the issue of ionizing radiation, technical aspects, indications and limitations of the method are presented and discussed in this article.

\section{ADVANCES IN ONCOLOGY}

The biological characteristics of tumors influence the spectrum of the disease presentations ${ }^{(13)}$. There are malignant chest lesions whose behavior is benign, indolent and mildly aggressive, with no clinical manifestation. Usually in this context, the morphological alterations can hardly be recognized and may either be missed or incidentally identified, particularly in cases of early-stage tumors with none or few symptoms. However, there are chest lesions with noticeable signs of destruction, with a huge dissemination potential and frequently associated with clinical manifestations such as asthenia, pain and weight loss. Frequently, such lesions present an aggressive biological behavior, facilitating the recognition of morphological alterations as well as the identification of the affected organs ${ }^{(14)}$.

Functional imaging methods usually detect disease activity before the onset of morphological manifestations ${ }^{(15)}$. With the development and dissemination of PET/CT, the functional tools gained more prominence over the last years $^{(16)}$. This method allowed for the recognition of regions avid for glucose and its molecular analogues such as fluorodeoxyglucose $\left({ }^{18} \text { FDG) (Figure } 1\right)^{(17)}$. Such regions may correspond to sites of tumor involvement and their evaluation as a whole by conventional morphological imaging methods such as CT and MRI provides greater anatomical detail, improving the quality of the information and the management of the patients ${ }^{(18-20)}$.

Over the last years, a significant development was observed in invasive, minimally invasive and noninvasive thoracic diagnostic work-up methods ${ }^{(21)}$. The evolution of techniques such as bronchoscopy, videothoracoscopy, mediastinoscopy, endobronchial endoscopic ultrasonography and imaging-guided transthoracic procedures significantly improved the evaluation of patients with chest tumors ${ }^{(22)}$. A significant advance in the locoregional therapeutic and sys-

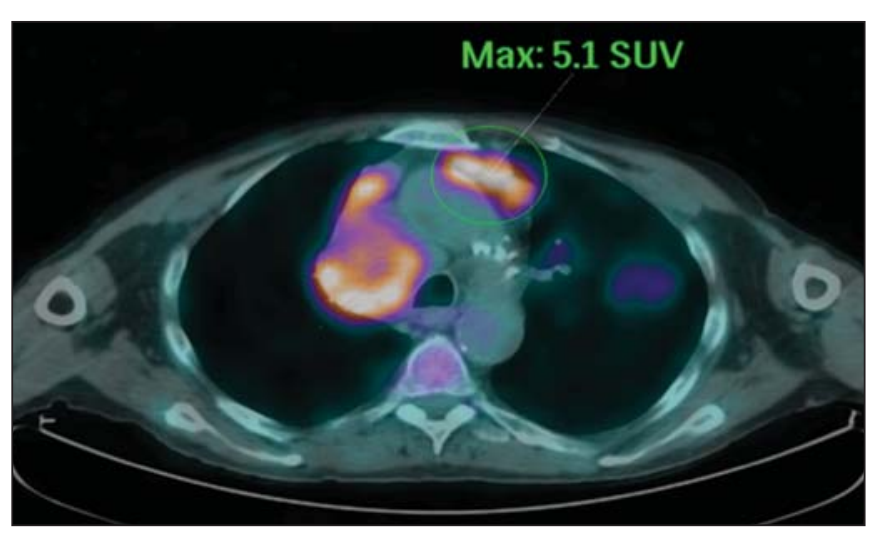

Figure 1. Female, 64-year-old patient with diagnosis of pulmonary adenocarcinoma in the right upper lobe. Intense radiopharmaceutical FDG uptake (hypersignal) is observed in the right lung lesion and contralateral para-aortic lymph nodes, the latter with standard uptake value (SUV) of 5.1, corresponding to clinical stage N3.

temic management of such patients was observed with the improvement of radiotherapy techniques and the introduction of new chemotherapy drugs, with impact on the quality of life of patients and increase in their survival rates ${ }^{(21)}$.

We are currently experiencing the age of the personalized therapy, also known as targeted cancer therapy that is based on the individual treatment of the patient ${ }^{(23)}$. Currently, the exclusive analysis of the histological type of the lesion is not sufficient for a more appropriate oncological management. Each patient and each lesion present their own characteristics and identity. A joint analysis of these elements is required to define the most appropriate therapeutic option ${ }^{(24)}$. We have passed from an age of predominantly morphological therapy based on the histological type and cellular death to an age of predominantly molecular therapy based on functional aspects, biomarkers profile and interruption of cell proliferation ${ }^{(23,24)}$.

The therapeutic advance was followed by the introduction of new imaging diagnosis technologies ${ }^{(25)}$. There was a significant evolution of MRI with the development of highfield apparatuses, new hardware and software, ultrafast parallel acquisition techniques, respiratory and cardiac synchronization as well as new functional and dynamic sequences allowing for a significant advance in the images quality ${ }^{(9)}$. Such a gain in quality represented a progress in the diagnostic performance of the method, allowing for a more appropriate evaluation of chest lesions as compared with the performance observed in the past ${ }^{(8,9)}$. The evaluation of the traditional morphological parameters such as size, shape, contours and relationship with adjacent structures, has significantly evolved, improving the therapeutic planning ${ }^{(6)}$. The introduction of dynamic parameters such as cine-MRI has added new information regarding infiltration of chest wall, mediastinal and vascular structures, strengthening the resectability criteria during the therapeutic planning ${ }^{(26)}$. On the other hand, the introduction of metabolic and functional parameters, such as perfusion and diffusion has added relevant information regarding the tumor activity, allowing for their application in different phases of the cancer patient manage- 
ment such as diagnosis, evaluation of therapeutic response and post-therapy follow-up ${ }^{(27)}$.

\section{IONIZING RADIATION}

Several studies in the literature approach the risks of ionizing radiation exposure involved in the use of different imaging diagnosis methods ${ }^{(28-30)}$. Such studies have demonstrated a great variation in the accumulated dose, depending on the exposure frequency and intensity. Also, one has identified the need for reduction of the dose to the lowest possible level, according to the ALARA (as low as reasonably achievable) principle, without impairing the evaluation and interpretation of the images ${ }^{(29,30)}$. Such a preoccupation should be enhanced in cases involving children, youth and pregnant women, considering the risks of cumulative effect of ionizing radiation ${ }^{(30,31)}$. The more sensitive the exposed biological tissue and the higher the exposure frequency and intensity, the greater is the risk ${ }^{(28)}$. The accumulation of radiation over a lifetime will be greater the earlier the individual is exposed. The possibility of development of a second primary tumor, such as leukemia or a brain tumor arising from early and inadvertent exposure is not negligible, particularly in cases of pediatric patients in the developmental phase ${ }^{(31-33)}$. Therefore, an effort to reduce ionizing radiation exposure to a minimum level without impairing the images quality is the main objective of those working in the field of imaging diagnosis ${ }^{(34)}$. This can be achieved with the use of a commercially available software specifically designed for dose reduction or simply by the adequacy of technical parameters, optimization of the number of sections and sequences, and reduction of $\mathrm{kV}$ and $\mathrm{mAs}{ }^{(34)}$. Another possibility is the utilization of diagnostic tools exempt from the risk inherent to ionizing radiation exposure such as MRI, for example, instead of the conventional radiological methods ${ }^{(11)}$. It is important to highlight that recent advances in the MRI technique have allowed for the introduction of radiological biomarkers which, as appropriately employed, contribute decisively to the diagnosis, staging and therapeutic response prediction. Depending on the clinical indication or on the phase of cancer management, the conventional radiation emitting radiological methods may be either replaced or complemented by MRI, which contributes to the reduction of radiation exposure risks ${ }^{(11)}$.

\section{TECHNICAL ASPECTS}

The scans should preferentially performed with the patient in supine position, in apparatuses of at least 1.5 tesla, with a body coil, maximum gradient strength of $33 \mathrm{mT} / \mathrm{m}$ slew rate of $160 \mathrm{mT} / \mathrm{m} / \mathrm{s}^{(9)}$. The images should preferentially acquired under apnea or during regular breathing, especially in the acquisition of longer sequences ${ }^{(9,10)}$. In the cases of non-collaborative, anxious, claustrophobic patients or children, it is recommended the MRI scan be performed under sedation or anesthesia. Usually, the images acquisition time varies between 15 and 30 minutes. Most frequently, the functional techniques and the use of intravenous contrast agents are responsible for the increase in the acquisition time $e^{(9,10)}$.

In order to minimize the occurrence of artifacts caused by respiratory motion, the acquisition of ultrafast sequences should be performed by means of echo-planar (EPI) or turboFLASH imaging, thus avoiding interferences during the images reconstruction. Such techniques are very fast and allow for images acquisition in $50 \mathrm{~ms}$, literally promoting a "freezing" of the physiological movement, being widely utilized in the acquisition of diffusion-weighted sequences. These technical steps are aimed at avoiding the occurrence of motion artifacts that affect the quality of the im$\operatorname{ages}^{(6,9,10,35)}$.

\section{Protocol}

Depending on the manufacturer, on the available softwares, the scan objective and on the lesion location, different types of sequences can be performed and acquired in different planes ${ }^{(6,9)}$. It is recommendable to perform in-phase and out-of-phase $\mathrm{T} 1$-weighted sequences with the fat-suppression technique. Also, such sequence may be performed after paramagnetic contrast injection, as indicated. The T2weighted sequences should be routinely performed with and without fat suppression ${ }^{(10)}$. The joint analysis of these sequences allows for a greater contrast between normal anatomical structures and areas affected by the tumor, increasing the method reliability ${ }^{(9,10,35)}$. The introduction of new morphological and functional techniques has also significantly contributed to an appropriate management of cancer patients. Techniques such as diffusion, perfusion and cine-MRI have widened the use of MRI in the evaluation of malignant chest lesions ${ }^{(26,36-38)}$. They may be indicated according to the lesion location, disease extent, available therapeutic options, and detection of recurrence after the treatment completion ${ }^{(7,24,27)}$.

\section{Diffusion-weighted imaging}

Similarly to PET/CT, diffusion-weighted sequence allows for the evaluation of biomolecular aspects of the tumor behavior by means of qualitative and quantitative parameters ${ }^{(39,40)}$. Usually, two criteria are utilized to classify the lesions detected on such sequence into malignant or benign, namely, the qualitative criterion related to the signal intensity (brightness), and the quantitative criterion defined by the absolute value of the apparent diffusion coefficient (ADC) within the lesion ${ }^{(41,42)}$. Based on such characteristics, it is possible to estimate the lesion cellularity and indicate whether such parameter favors a diagnosis of benignity of malignancy. Benign lesions generally do not present any sign of water molecules diffusion restriction and, consequently, present low signal intensity on this sequence and ADC levels $>1.0 \times 10^{-3}$ $\mathrm{mm}^{2} / \mathrm{s}$ (Figure 2). On the other hand, malignant tumors generally present water molecules diffusion restriction secondary to cell proliferation, frequently with increased signal 
intensity at the diffusion-weighted image and ADC levels $<1.0 \times 10^{-3} \mathrm{~mm}^{2} / \mathrm{s}$ (Figure 3) $)^{(39-42)}$. The ADC calculation is carried out by means of linear regression analysis of the natural signal intensity log versus the gradient factor, in accordance with the following equation:

$$
A D C=-(\operatorname{In}(S h / S i)) /(b h-b i)
$$

where: $S h$ and $S i$ correspond to the signal intensities in the region of interest obtained by the difference between these two gradient factors ( $b h$ and $b i$ ). The maximum gradient factor $(b h)$, corresponding to $600 \mathrm{~s} / \mathrm{mm}^{2}$, and the minimum gradient factor $(b i)$, corresponding to $00 \mathrm{~s} / \mathrm{mm}^{2}$, usually are sufficient for an appropriate diffusion-weighted imaging of oncologic chest diseases $^{(9,10,40-42)}$.
The images are analyzed for the definition of the regions of interest and submitted to diffusion-weighted study on the basis of the adopted criteria. The lesion signal intensity and ADC value in $\mathrm{mm}^{2} / \mathrm{s}$ should be analyzed as a function of location, size and areas of viable tumor, by selecting the regions of interest (ROIs) in accordance with the interpretation of the images by the radiologist. One should always select the ROI that is more representative of the lesion, excluding areas of necrosis, calcifications, gaseous material or areas affected by any type of partial volume adjacent to the lesion ${ }^{(40-42)}$.

The images should be filed utilizing a digital system and transferred to a workstation. The diffusion-weighted sequence should be post-processed with the aid of commercially avail-

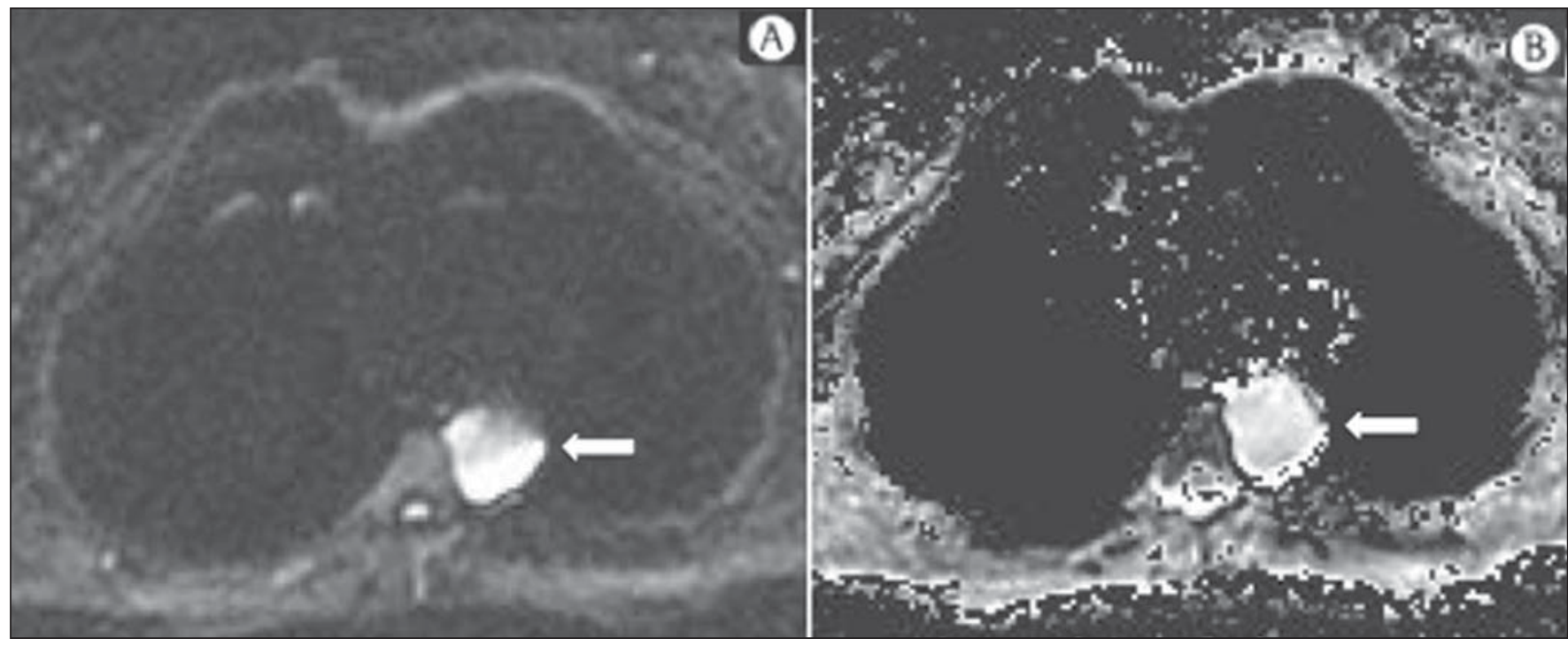

Figure 2. Female, 23-year-old patient with neurofibromatosis, presenting with left paravertebral lesion in close contact with the neural foramen. On A, high signal intensity is observed on the diffusion-weighted image (arrow). On B, the same lesion is observed (arrow) on the ADC map, presenting values $>1 \mathrm{~mm}^{2} / \mathrm{s}$ (not demonstrated), corresponding to lower cellularity and little water molecules diffusion restriction. This lesion was considered as little aggressive, a probable schwannoma corroborated by the findings on the other sequences. Considering the age of the patient as well as the benign appearance/low aggressiveness of the lesion, one has opted for semestral follow-up of the lesions by means of MRI.

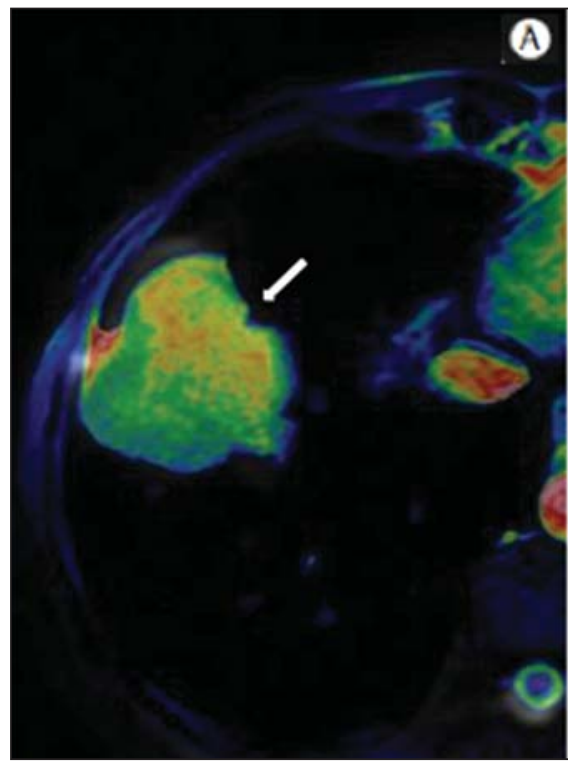

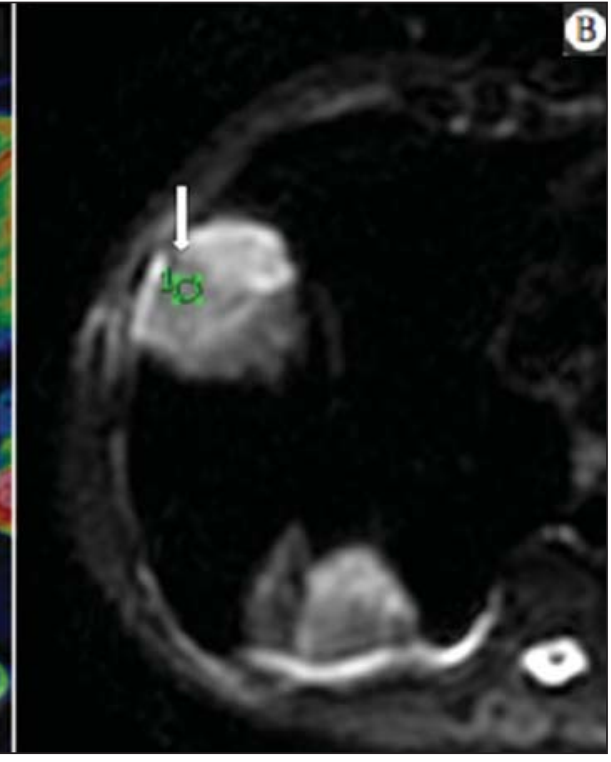

Figure 3. Male, 54-year-old with colon adenocarcinoma progressing with pulmonary nodule suggestive of metastasis. Chest MRI demonstrates a solid nodule in the right upper lobe. On A, the nodule presents heterogeneous hyperintensity (arrow) of the signal on the diffusion-weighted sequence. On B, ADC map demonstrates values $<1 \mathrm{~mm}^{2} / \mathrm{s}$ within the lesion, corresponding to high cellularity and water molecules diffusion restriction suggesting malignancy. The nodule was biopsied and the diagnosis of metastasis was confirmed. 
able softwares with the objective of obtaining the ADC maps. The ADC maps may be represented by color shades such as, for example, black and white, where black usually represents restricted diffusion, and white, absence of diffusion restriction. The same happens for the other colors.

\section{Perfusion-weighted imaging}

Perfusion-weighted sequence offers the possibility of evaluating the pulmonary vascular bed perfusion on T1weighted gradient-echo images by means of ultra-fast acquisition during paramagnetic contrast (gadolinium chelates) injection $^{(37,43)}$, allowing for the visualization of the regional blood flow, with possibility of quantification of such flow in different ways. The acquisition of thre-dimensional sequences following intravenous contrast injection allows for the characterization of vessels of different calibers, and may be employed in the evaluation of pulmonary perfusion ${ }^{(38,44)}$. Several studies have already demonstrated the feasibility of this technique to evaluate both normal and pathological processes. It has been utilized in chest studies to subjectively evaluate perfusion, particularly in cases of pulmonary embolism and cystic fibrosis ${ }^{(44-46)}$. Tissues with high vascularization and high capillary permeability, i.e. suspicious of malignancy, tend to be early and intensely opacified by the contrast as compared with poorly vascularized tissues that most frequently are associated with less aggressive lesions ${ }^{(45,46)}$. With this technique, tumor lesions can be qualitatively evaluated by means of signal intensity-time curves and quantitatively evaluated by calculating the curve numeric value in percentage of signal increase per minute. One can estimate the tumor angiogenesis pattern by considering the time the contrast agent took to cover the lesion on this imaging sequence. The enhancement and perfusion curves pat- tern provides relevant information about the biological behavior of the tumors (Figure 4) $)^{(44-46)}$.

\section{Cine-MRI}

Cine-MRI originated from heart studies and is nothing more than a dynamic evaluation of the chest taking respiratory and cardiac movements into consideration. The images can be obtained by means of synchronization between cardiac and respiratory movements ${ }^{(25)}$. Such a technique allows for a detailed study of large vessels and a dynamic evaluation of the vascular flow, particularly of the aorta, supra-aortic arteries, pulmonary arteries and its main branches, superior vena cava and brachioencephalic veins. Cine-MRI adds diagnostic accuracy in the prediction of invasion of the chest wall bronchovascular hilar and mediastinal structures in the presence of chest tumors (Figure 5) 26,47$)$.

\section{INDICATIONS}

A range of tumor lesions may affect the chest, from tumors of epithelial origin such as breast, lung, tracheal, esophageal, thymic carcinomas, and embryonic germ cell carcinomas to tumors of mesenchymal origin, including liposarcomas, osteosarcomas, leiomyosarcomas and lympho$\operatorname{mas}^{(15,35,36,40,41,43,48,49)}$. The chest is also a frequent site of metastatic implants from originally primary tumors or from extrathoracic tumors, either by lymphatic or hematogenous dissemination or by contiguity ${ }^{(40-42)}$.

MRI allows for an appropriate evaluation of the chest and may be employed to evaluate lesions in different anatomical structures, including, particularly, chest wall lesions (Figure 6), vertebral spine (Figure 7), pleura, pulmonary parenchyma (Figure 3), mediastinum (Figure 8), heart (Figure 7), esophagus (Figure 9), and lymph nodes (Figure 9).

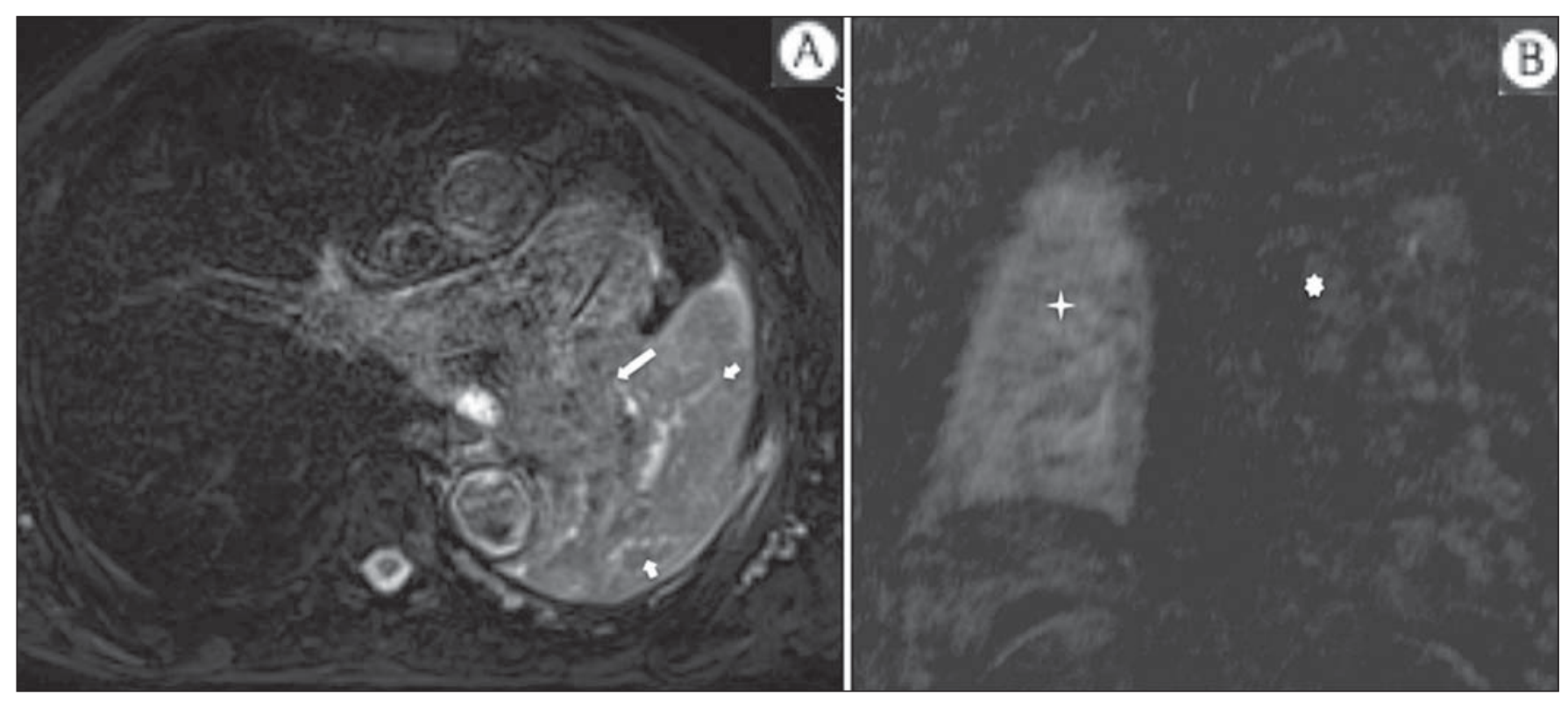

Figure 4. Male, 75-year-old patient with chronic obstructive pulmonary disease and previous history of lung cancer resection for two years. Currently, there is a suspicion of recurrence. On A, MRI T2-weighted fatsat sequence could detect the presence os a central nodule at left (long arrow) in the area of post-obstructive pneumonitis (short arrows). On B, pulmonary perfusion-weighted sequence demonstrates absence of perfusion in the remnant left lung. 

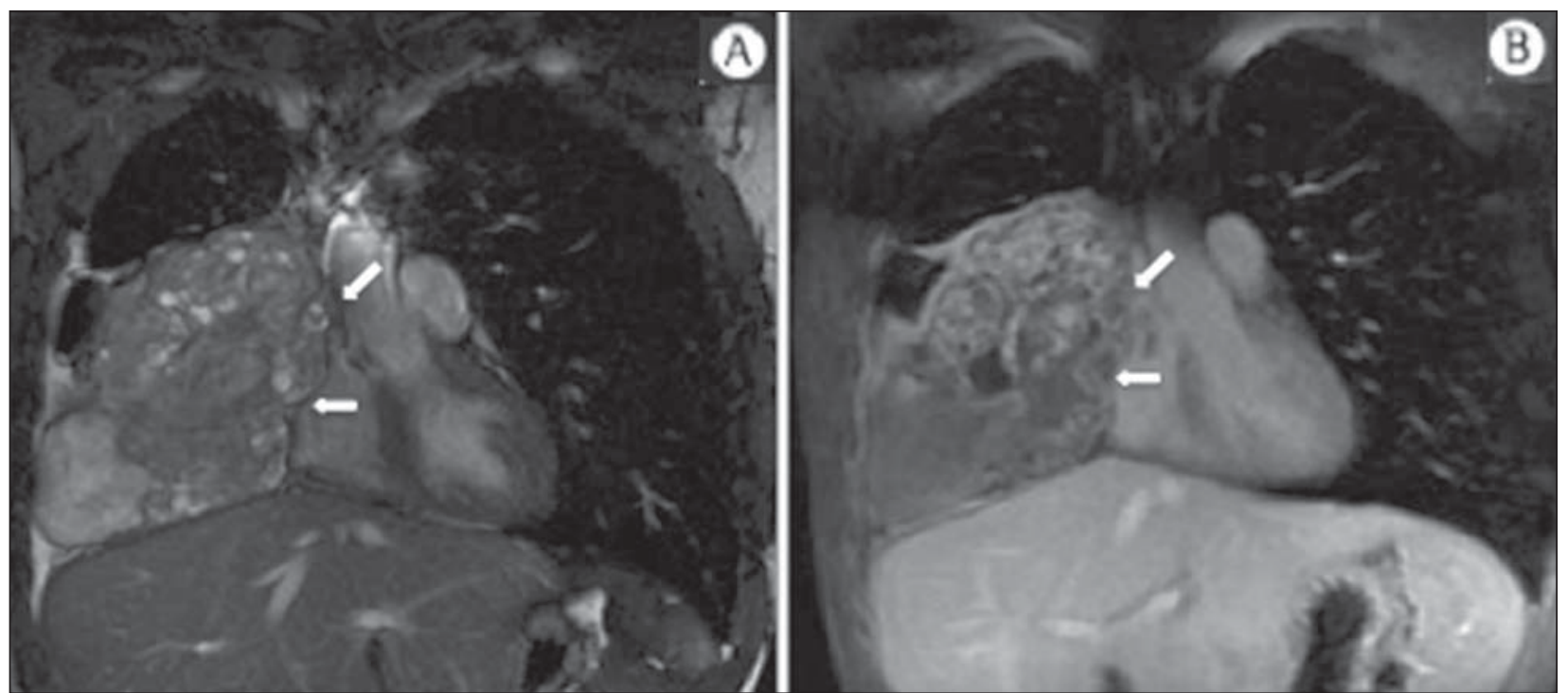

Figure 5. Male, 22-year-old patient with a malignant nonseminomatous germ cell tumor. On $\mathbf{A}$ and $\mathbf{B}$, an anterior, heterogeneous mediastinal nodule with areas of necrosis is observed extending toward the right atrium and superior vena cava, with signs of invasion of these structures (arrows), contraindicating surgical resection. Complementary cine-MRI was performed, confirming the fixation/infiltration of the superior vena cava and right atrium by the nodule.

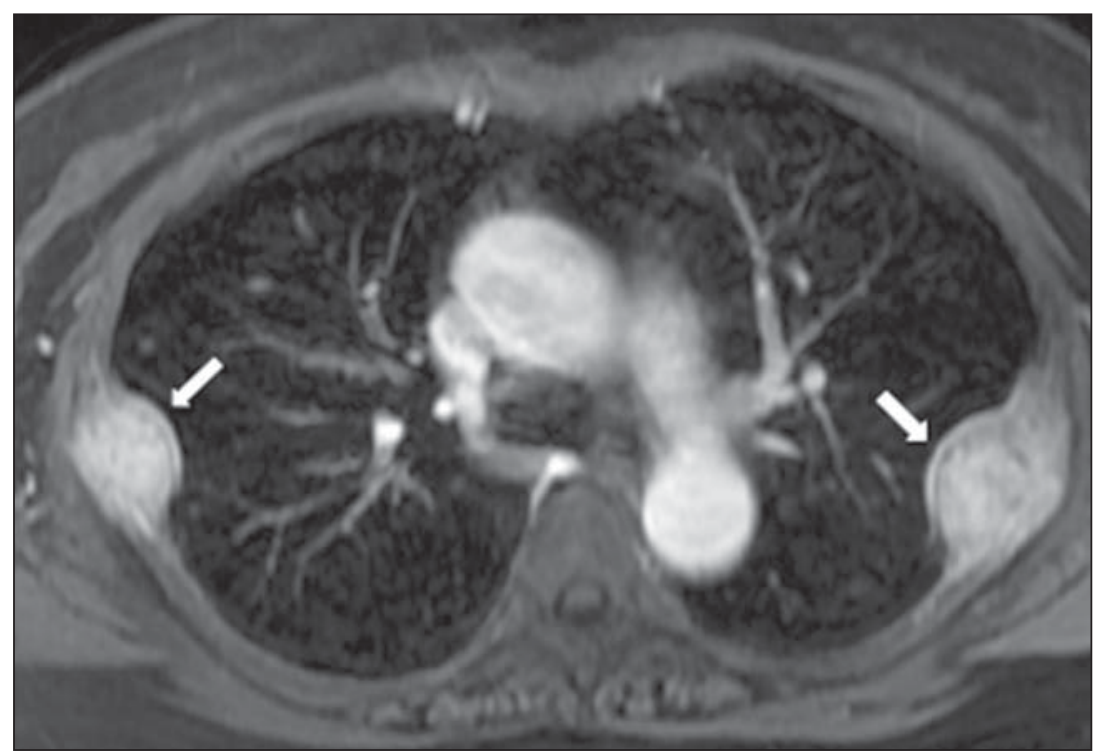

Figure 6. Patient 49-year-old with renal tumor progressing with bilateral chest pain. MRI T1-weighted sequence with fat suppression demonstrates coastal lesions with signal intensity of soft parts and intense paramagnetic contrast enhancement (arrows) suggestive of metastasis. Later, the diagnosis was histopathologically confirmed.
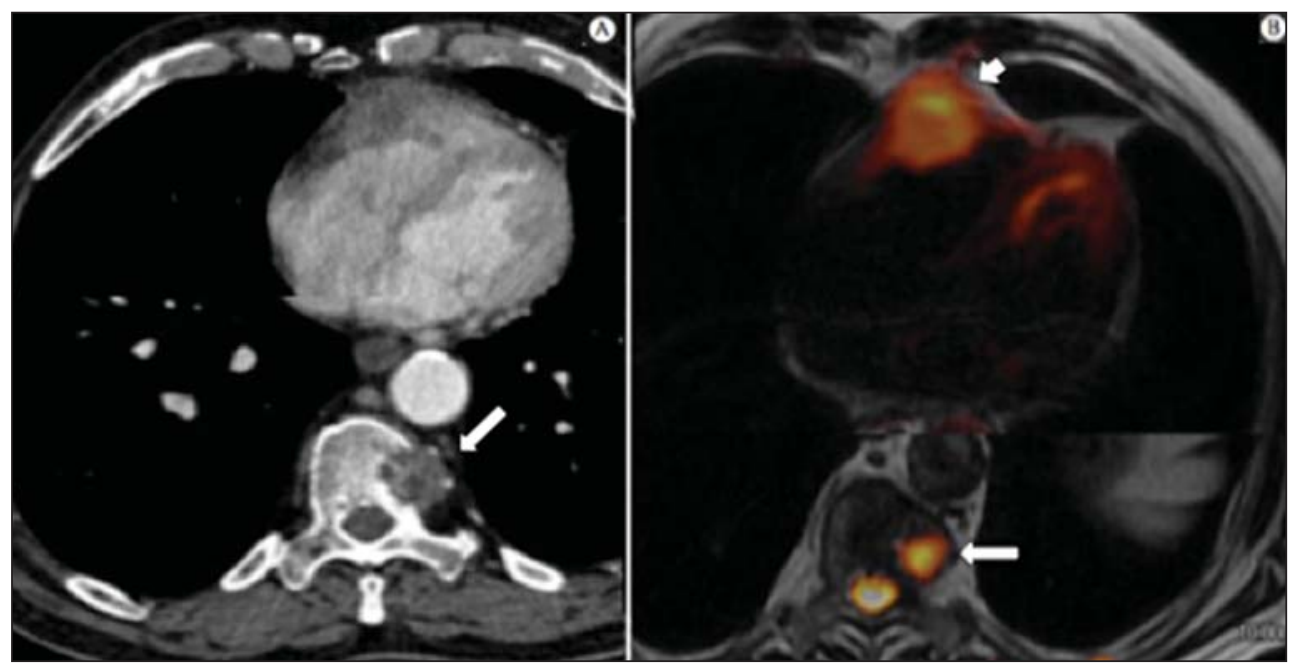

Figure 7. Male, 71-year-old patient with spinocellular carcinoma of the lung. On $\mathbf{A}$ chest CT demonstrates lytic lesion with soft parts component in the left vertebral hemibody (arrow) of an inferior thoracic vertebra. On B, fusion of a background anatomical T2-weighted image superimposed by the diffusion-weighted sequence, demonstrating marked hypersignal in the thoracic vertebral lesion (long arrow) and also on the anterior wall of the right ventricle (short arrow) compatible with areas of intense cellularity, suggestive of malignancy. 
Figure 8. Female, 21-year-old, with voluminous anterior expansile mediastinal lesion. On A, T2-weighted image demonstrating well-defined lesion (arrows) with regular contours, and with finely heterogeneous, slightly increased signal intensity on this sequence. Homogeneous and diffuse increase in signal is observed on the diffusionweighted sequence, and the ADC map demonstrated values $>1 \mathrm{~mm}^{2} / \mathrm{s}$ (not available) within the lesion, corresponding to low cellularity and little water molecules diffusion restriction. On B, the surgical specimen can be observed. The histopathological result confirmed the diagnosis of a well differentiated tumor: thymoma B1.
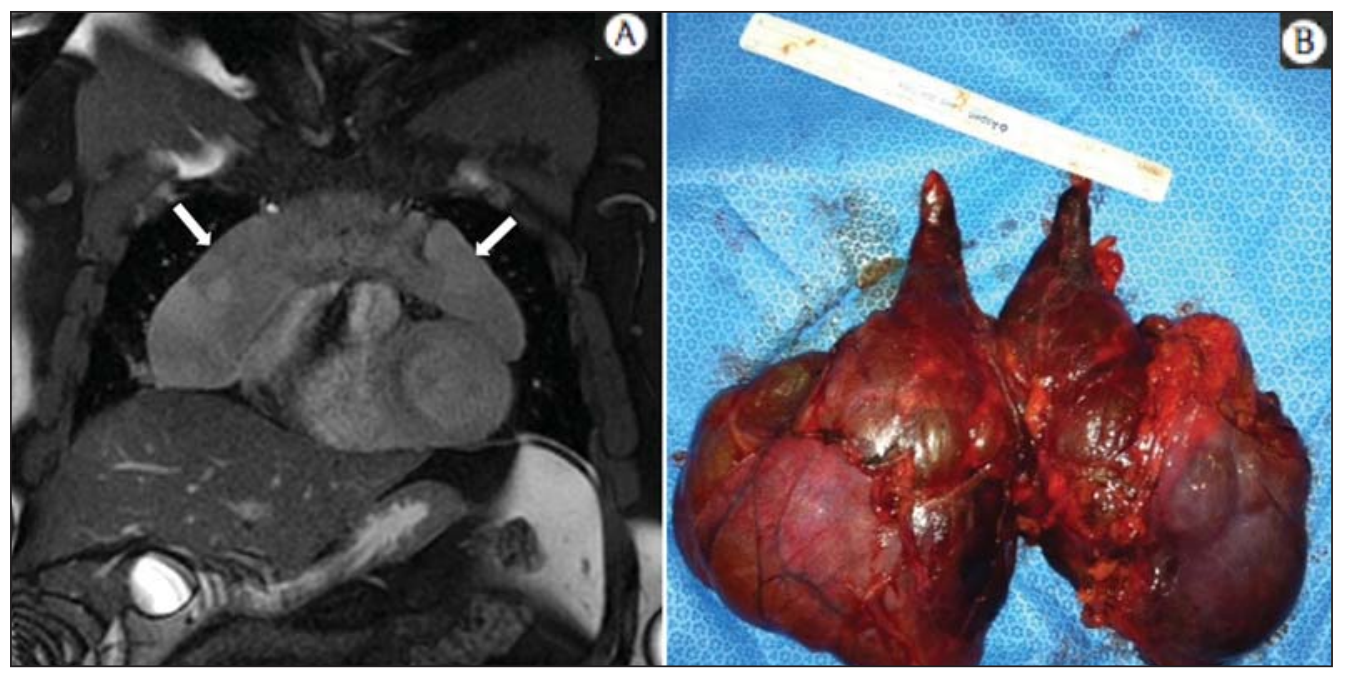

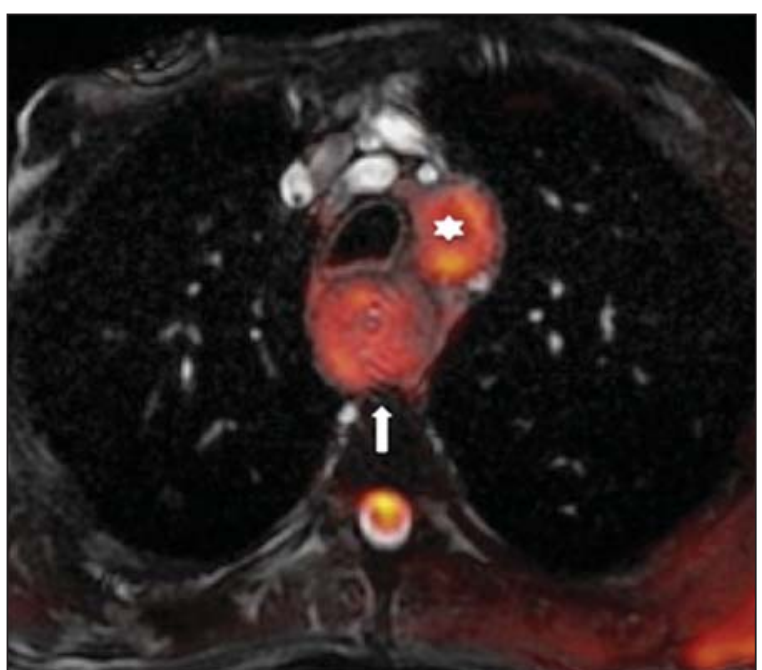

Figure 9. Male, 71-year-old patient with long history of smoking and alcoholism, developed esophageal spinocellular carcinoma. On this figure, there was a fusion of the background anatomical T2-weighted image with the diffusion-weighted image. Observe that the esophageal expansile lesion (arrow) and the left paratracheal lymph node enlargement (asterisk) present hypersignal on the diffusion-weighted sequence compatible with high cellularity. The diagnosis of malignancy was later confirmed by histopathological analysis.
The evaluation of structures affected by neoplastic lesions, their anatomical relationships and morphological and functional characteristics may be determined along the several phases of the cancer management, either at the diagnosis, biopsy guidance (Figure 10), locoregional staging, clinical therapeutic, surgical or radiotherapy planning (Figure 11), in the therapeutic response evaluation (Figure 12), or in the post-therapy follow-up ${ }^{(40-42)}$.

Patients with malignant chest lesions should undergo a detailed imaging evaluation. Over the last years, MRI has undergone huge developments and, as appropriately indicated, had demonstrated to be a promising and quite attractive option capable of improving the evaluation of cancer patients, contributing to a more appropriate conduct of the disease.

\section{LIMITATIONS AND CONTRAINDICATIONS}

The significant advances observed in MRI over the last years have resulted in images of excellent quality, frequently comparable to CT images, in the evaluation of the pulmonary parenchyma, even in cases of infectious, inflammatory diseases and interstitial pneumopathies ${ }^{(50)}$. In the evaluation

Figure 10. Patient 14-year-old, asymptomatic patient presenting with anterior mediastinal nodule detected at imaging study. On A, MRI ADC mapping performed to support biopsy planning, definition of needle pathway (long arrow) and selection of the area for sample collection, indicating the region with values $<1 \mathrm{~mm}^{2} / \mathrm{s}$ within the lesion (short arrow). On B, the gross needle pathway is seen at CT image. Note that, at CT, the needle pathway (arrow) coincides with the MRI planned pathway. Five biopsy specimens were collected and the anatomopathological analysis confirmed the diagnosis of thymoma B3.

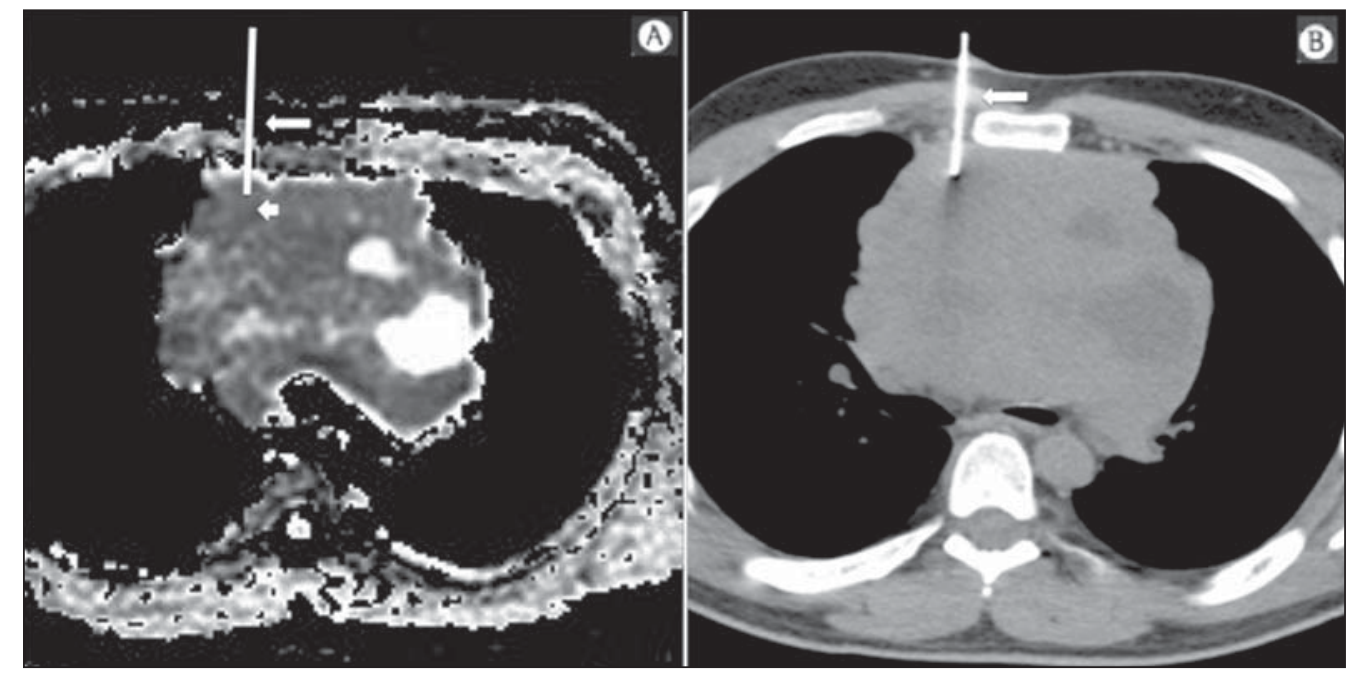




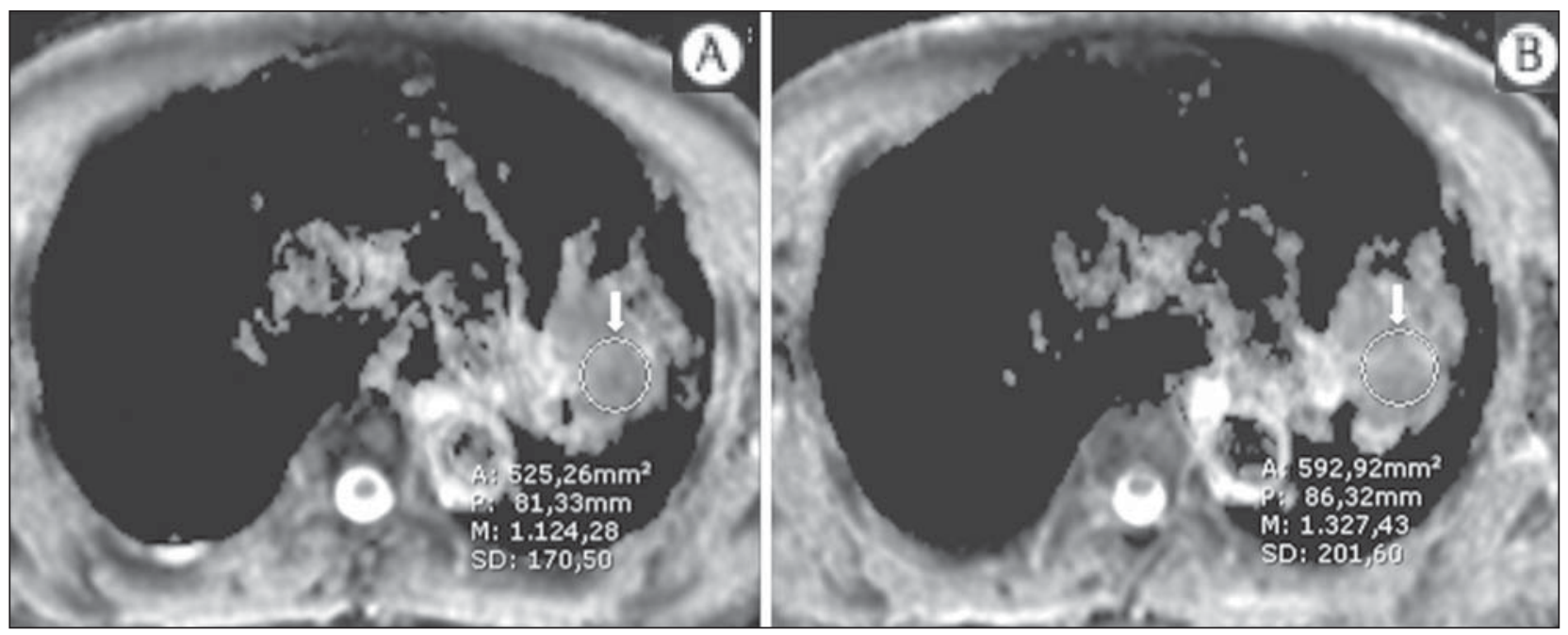

Figure 11. Male, 73-year-old patient with a central nodule at left in association with secondary atelectasis. Transbronchial biopsy confirmed the diagnosis of clinical stage Illa pulmonary adenocarcinoma. Chest MRI including ADC mapping was performed. ADC values were measured within the region of interest (circle). On A, the ADC mapping (arrow) performed before the neoadjuvant chemotherapy, and on B, ADC mapping (arrow) performed after neoadjuvant chemotherapy. Note the increase in ADC values (a sign of good response, cell necrosis), even without significant change in the nodule dimensions. The lesion was uneventfully resected and the diagnosis of predominantly micropapillary adenocarcinoma (tumor T3N2) was confirmed.

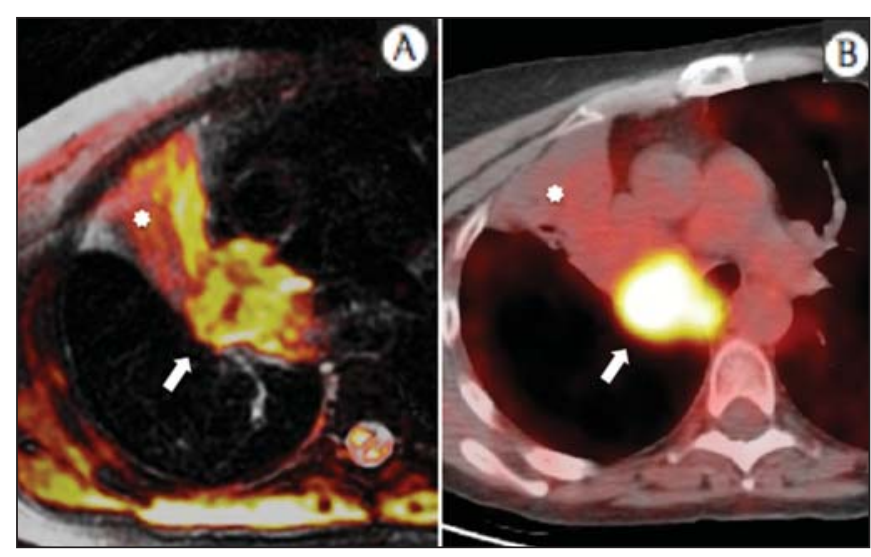

Figure 12. Male, 68-year-old patient with diagnosis of adenocarcinoma in the right upper lobe. On A, chest MRI including fusion between anatomical (T2-weighted) image and functional (diffusion-weighted) image, similarly to PET/CT imaging. Observe the central lesion in association with intense brightness (arrow) leading to post-obstructive pneumonitis characterized by the area of atelectasis with lower brightness (asterisk). On B, PET/CT image demonstrates central lesion in association with intense contrast uptake (arrow) corresponding to post-obstructive pneumonitis characterized by the area of atelectasis, without contrast uptake (asterisk).

of chest tumors, such advances have contributed to the differential diagnosis, detection of secondary findings and comorbidities $^{(50)}$.

However, some limitations still remain as obstacles to a greater popularization of this method and should be mentioned. As regards equipment, the use of high-field is required, with at least 1.5 tesla, including modern softwares and appropriate coils, which significantly increase the costs of the method. The images acquisition time is another limiting factor, since the scan usually takes about 15 minutes, and may exceed 30 minutes with the utilization of functional techniques and employment of intravenous contrast agents $^{(9,10)}$, i.e. much more time than that required for a CT scan. In cases of elderly, severely ill patients, those with degenerative bone alterations, those with bronchitis or emphysema, and those with chronic cough, there is a natural difficulty to remain at absolute rest, in supine position for many minutes, or to certain respiratory commands. Additionally, there is the issue of claustrophobia, impeding the patient to remain within the apparatus. In such situations, it is recommended that the scan is performed under sedation or anesthesia, which increases the risk of complications ${ }^{(9,10)}$. The presence of magnetic susceptibility artifacts, such as metal materials of prostheses or foreign bodies, and the presence of motion artifacts end up degrading the images which may represent a limiting factor do the interpretation of the images or even for the scan performance.

As regards the radiological team, a specific training is required to perform chest MRI and development of appropriate protocols for cancer evaluation. The presence of an experienced radiologist acting in a multidisciplinary way with the clinical oncology, radiotherapy, chest surgery and pulmonology teams enhances the MRI performance, increasing the method reliability as well as its utilization in the oncologic routine $\mathrm{e}^{(31-33)}$.

Chest MRI contraindications are similar to those for MRI in other parts of the body. A criterious evaluation is always necessary before a MRI scan. The multidisciplinary team should always evaluate the clinical condition of the patient and decide whether he/she can cope with the scan time or sedation/anesthesia will be necessary, weighting the risks and benefits. Other issue of extreme relevance is to verify if the patient has metal materials such as prostheses, catheters, pacemakers or other foreign bodies of similar nature in his/her body. Depending on the model, such devices may be damaged or displaced if submitted to the magnetic field effects. It is a duty of the radiological team to avoid such situations $^{(6,9,10,50)}$. 


\section{CONCLUSION}

MRI is an imaging method available in several specialized and nonspecialized health centers, and has been increasingly utilized in the evaluation of chest tumors because of its advantages. The excellent contrast and spatial resolution, the possibility of using dynamic and functional techniques and the absence of ionizing radiation risks make this tool quite attractive and promising in the management of cancer patients.

\section{Acknowledgements}

The Figures 4 and 11 were kindly provided by the Department of Diagnostic and Interventional Radiology of Heidelberg University, Germany, by courtesy of Prof. HansUlrich Kauczor.

\section{REFERENCES}

1. Ott JJ, Ullrich A, Mascarenhas M, et al. Global cancer incidence and mortality caused by behavior and infection. J Public Health (Oxf). 2011;33:223-33.

2. Schottenfeld D, Beebe-Dimmer JL, Buffler PA, et al. Current perspective on the global and United States cancer burden attributable to lifestyle and environmental risk factors. Annu Rev Public Health. 2013;34:97-117.

3. Bragg DG. State-of-the-art assessment. Diagnostic oncologic imaging. Cancer. 1989;64(Suppl):261-5; discussion 269-71.

4. López-Encuentra A, García-Luján R, Rivas JJ, et al. Comparison between clinical and pathologic staging in 2,994 cases of lung cancer. Ann Thorac Surg. 2005;79:974-9.

5. Adsay NV, Basturk O, Saka B. Pathologic staging of tumors: pitfalls and opportunities for improvements. Semin Diagn Pathol. 2012;29:103-8.

6. Hochhegger B, Marchiori E, Irion K, et al. Magnetic resonance of the lung: a step forward in the study of lung disease. J Bras Pneumol. 2012;38:105-15.

7. García Figueiras R, Padhani AR, Vilanova JC, et al. Functional imaging of tumors. Part 1. Radiologia. 2010;52:115-25.

8. Kauczor HU, Ley S. Thoracic magnetic resonance imaging 1985 to 2010. J Thorac Imaging. 2010;25:34-8.

9. Kauczor HU, Ley-Zaporozhan J, Ley S. Imaging of pulmonary pathologies: focus on magnetic resonance imaging. Proc Am Thorac Soc. 2009;6:458-63.

10. Puderbach M, Hintze C, Ley S, et al. MR imaging of the chest: a practical approach at 1.5T. Eur J Radiol. 2007;64:345-55.

11. Guimaraes MD, Gross JL, Chojniak R, et al. MRI-guided biopsy: a valuable procedure alternative to avoid the risks of ionizing radiation from diagnostic imaging methods. Cardiovasc Intervent Radiol. 2014;37:858-60.

12. Takenaka D, Ohno Y, Matsumoto K, et al. Detection of bone metastases in non-small cell lung cancer patients: comparison of wholebody diffusion-weighted imaging (DWI), whole-body MR imaging without and with DWI, whole-body FDG-PET/CT, and bone scintigraphy. J Magn Reson Imaging. 2009;30:298-308.

13. Richman SD, Chambers P, Seymour MT, et al. Intra-tumoral heterogeneity of KRAS and BRAF mutation status in patients with advanced colorectal cancer (aCRC) and cost-effectiveness of multiple sample testing. Anal Cell Pathol (Amst). 2011;34:61-6.

14. Chowdhury S, Ongchin M, Sharratt E, et al. Intra-tumoral heterogeneity in metastatic potential and survival signaling between isoclonal HCT116 and HCT116b human colon carcinoma cell lines. PLoS One. 2013;8:e60299.
15. Nava D, Oliveira HC, Luisi FA, et al. Aplicação da ressonância magnética de corpo inteiro para o estadiamento e acompanhamento de pacientes com linfoma de Hodgkin na faixa etária infanto-juvenil: comparação entre diferentes sequências. Radiol Bras. 2011; $44: 29-34$.

16. Asai N, Ohkuni Y, Shoji K, et al. Efficacy of 18F-fluorodeoxyglucose positron emission tomography/computed tomography in evaluating lung cancer recurrence. J Bras Pneumol. 2013;39:242-4.

17. Dias OM, Lombardi EM, Canzian M, et al. 18F-fluorodeoxyglucose positron emission tomography as a noninvasive method for the diagnosis of primary pulmonary artery sarcoma. J Bras Pneumol. 2011;37:817-22.

18. Schwenzer NF, Pfannenberg C, Reischl G, et al. Application of MR/PET in oncologic imaging. Rofo. 2012;184:780-7.

19. Berker Y, Franke J, Salomon A, et al. MRI-based attenuation correction for hybrid PET/MRI systems: a 4-class tissue segmentation technique using a combined ultrashort-echo-time/Dixon MRI sequence. J Nucl Med. 2012;53:796-804.

20. Yankeelov TE, Peterson TE, Abramson RG, et al. Simultaneous PET-MRI in oncology: a solution looking for a problem? Magn Reson Imaging. 2012;30:1342-56.

21. Vallières E, Peters $S$, Van Houtte $P$, et al. Therapeutic advances in non-small cell lung cancer. Thorax. 2012;67:1097-101.

22. Campo-Cañaveral de la Cruz JL, Herrero Collantes J, Sánchez Lorente D, et al. Chest wall surgery. Arch Bronconeumol. 2011;47 Suppl 3:15-24.

23. Kalia M. Personalized oncology: recent advances and future challenges. Metabolism. 2013;62 Suppl 1:S11-4.

24. Figueiras RG, Padhani AR, Goh VJ, et al. Novel oncologic drugs: what they do and how they affect images. Radiographics. 2011;31: 2059-91.

25. Goldfarb R, Ongseng F, Finestone H, et al. Oncologic imaging: state of the art and research priorities. Am J Clin Oncol. 1989;12: 178.

26. Kajiwara N, Akata S, Uchida O, et al. Cine MRI enables better therapeutic planning than $\mathrm{CT}$ in cases of possible lung cancer chest wall invasion. Lung Cancer. 2010;69:203-8.

27. Martí-Bonmatí L, Sopena R, Bartumeus P, et al. Multimodality imaging techniques. Contrast Media Mol Imaging. 2010;5:180-9.

28. Chawla SC, Federman N, Zhang D, et al. Estimated cumulative radiation dose from PET/CT in children with malignancies: a 5year retrospective review. Pediatr Radiol. 2010;40:681-6.

29. Calegaro JUM. Baixos níveis de radiação ionizante causam câncer? Radiol Bras. 2007;40(4):ix-X.

30. Hall EJ, Brenner DJ. Cancer risk from diagnostic radiology: the impact of new epidemiological data. Br J Radiol. 2012;85:e1316-7.

31. Brenner DJ, Hall EJ. Cancer risk from CT scans: now we have data, what next? Radiology. 2012;265:330-1.

32. Brenner DJ. Effective dose: a flawed concept that could and should be replaced. Br J Radiol. 2008;81:521-3.

33. Sachs RK, Brenner DJ. Solid tumor risks after high doses of ionizing radiation. Proc Natl Acad Sci U S A. 2005;102:13040-5.

34. O'Neill SB, O'Connor OJ, McWilliams SR, et al. Minimization of radiation exposure due to computed tomography in inflammatory bowel disease. Clin Res Hepatol Gastroenterol. 2011;35:105-10.

35. Santos MK, Elias J Jr, Mauad FM, et al. Magnetic resonance imaging of the chest: current and new applications, with an emphasis on pulmonology. J Bras Pneumol. 2011;37:242-58.

36. Hochhegger B, Marchiori E, Irion K, et al. MRI in assessment of lung cancer. Thorax. 2011;66:357.

37. Razek AA. Diffusion magnetic resonance imaging of chest tumors. Cancer Imaging. 2012;12:452-63.

38. Ley S, Mereles D, Risse F, et al. Quantitative 3D pulmonary MRperfusion in patients with pulmonary arterial hypertension: correla- 
tion with invasive pressure measurements. Eur J Radiol. 2007;61: $251-5$.

39. Testa ML, Chojniak R, Sene LS, et al. Ressonância magnética com difusão: biomarcador de resposta terapêutica em oncologia. Radiol Bras. 2013;46:178-80.

40. Koh DM, Takahara T, Imai Y, et al. Practical aspects of assessing tumors using clinical diffusion-weighted imaging in the body. Magn Reson Med Sci. 2007;6:211-24.

41. Padhani AR, Liu G, Koh DM, et al. Diffusion-weighted magnetic resonance imaging as a cancer biomarker: consensus band recommendations. Neoplasia. 2009;11:102-25.

42. Padhani AR, Koh DM. Diffusion MR imaging for monitoring of treatment response. Magn Reson Imaging Clin N Am. 201 1;19:181209.

43. Hochhegger B, Marchiori E, Sedlaczek O, et al. MRI in lung cancer: a pictorial essay. Br J Radiol. 2011;84:661-8.

44. Ohno Y, Hatabu H, Murase K, et al. Primary pulmonary hypertension: 3D dynamic perfusion MRI for quantitative analysis of regional pulmonary perfusion. AJR Am J Roentgenol. 2007;188:48-56.
45. Hopkins SR, Garg J, Bolar DS, et al. Pulmonary blood flow heterogeneity during hypoxia and high-altitude pulmonary edema. Am J Respir Crit Care Med. 2005;171:83-7.

46. Hochhegger B, Ley-Zaporozhan J, Marchiori E, et al. Magnetic resonance imaging findings in acute pulmonary embolism. Br J Radiol. $2011 ; 84: 282-7$.

47. Akata S, Kajiwara N, Park J, et al. Evaluation of chest wall invasion by lung cancer using respiratory dynamic MRI. J Med Imaging Radiat Oncol. 2008;52:36-9.

48. Vilela TT, Daher RT, Nóbrega MDA, et al. Cistos congênitos do mediastino: aspectos de imagem. Radiol Bras. 2009;42:57-62.

49. Marques EF, Medeiros MLL, Souza JA, et al. Indicações de ressonância magnética das mamas em um centro de referência em oncologia. Radiol Bras. 2011;44:363-6.

50. Barreto MM, Rafful PP, Rodrigues RS, et al. Correlation between computed tomographic and magnetic resonance imaging findings of parenchymal lung diseases. Eur J Radiol. 2013;82:e492-501. 